\title{
Location influences size-selective predation on newly settled reef fish
}

\author{
Thomas H. Holmes, Mark I. McCormick* \\ School of Marine Biology and Aquaculture, James Cook University, Townsville, Queensland 4811, Australia
}

\begin{abstract}
Demersal fish usually settle to established fish assemblages that include suites of gapelimited predators, whose compositions vary among locations. We investigated the extent to which predation was size-selective on a species of newly settled coral reef fish, the damselfish Pomacentrus amboinensis (Bleeker 1868), among 3 lagoonal sites on 1 reef. The 3 sites at Lizard Island, Great Barrier Reef, Australia, differed in species composition and relative abundance of predators. Fish at the end of their larval phase were caught in light traps and tattooed for individual recognition. They were then paired so that there was a $1 \mathrm{~mm}$ difference between partners, and placed on small patch reefs at the base of the 3 shallow lagoonal sites. Large individuals survived significantly better than small individuals in 1 out of 3 sites. One site displayed the reverse trend, even though non-significant, and the third site showed no evidence of selection. Selection was strongest at the site where predators of small reef fishes were in highest densities and water currents were strongest. Strong water currents appeared to emphasise size-related differences in swimming ability and increase the vulnerability of small fish at this site. Our results suggested that the occurrence of size-selection for this species at settlement will depend on the composition of the predator assemblage and prevailing environmental conditions; these both interact with the performance attributes of prey, and all 3 variables may be location-specific.
\end{abstract}

KEY WORDS: Predation - Body size $\cdot$ Size-selectivity $\cdot$ Coral reef fish $\cdot$ Settlement $\cdot$ Juvenile Pomacentrus amboinensis

\section{INTRODUCTION}

Predation is known to be a major source of mortality for most larval and juvenile fishes in the marine environment (Bailey \& Houde 1989, Planes \& Lecaillon 2001, Doherty et al. 2004). Recent studies have shown that the early post-settlement life stage exhibits exponential mortality curves, with upwards of $57 \%$ of individuals being lost within the first $48 \mathrm{~h}$ (Booth 1991, Webster 2002, Doherty et al. 2004, McCormick \& Hoey 2004). This high mortality is potentially important for 2 reasons: (1) fluctuations in the number of juveniles may regulate the size of the local adult population (Doherty \& Fowler 1994), and (2) because the mortality rate is higher during this early stage than at any other time during settled life, this early mortality will have a disproportionate influence on the distribution of body attributes and life history traits in the population, particularly if mortality is selective (Caley 1998). If mortality is not selective, then high mortality alone does not necessarily indicate a critical life stage for population regulation or for life history evolution (e.g. Crouse et al. 1987). Despite the obvious importance of predatory processes during the period immediately following settlement, little is currently known of the interaction between early post-settlement fish and their predators.

At settlement, individuals can differ in a number of characteristics that may influence survival during a predatory encounter (e.g. morphometrics, biochemical condition, sensory development, locomotory performance; McCormick 1998, Booth 2002, Booth \& Beretta 2004). Of these, body size has received the most attention in the literature, and is widely thought to be the 
most important prey characteristic to determine the outcome of predator-prey encounters (Rice et al. 1997, Schmitt \& Holbrook 1999, McCormick \& Hoey 2004). One body of theory suggests that large prey should exhibit higher survival than smaller counterparts due to the performance attributes that correlate with size ('bigger-is-better', Leggett \& Deblois 1994), such as burst speed. There are known to be moderate levels of variability in body size at the time of settlement among many reef fish species (McCormick \& Molony 1993, Kerrigan 1997, Booth 2002), and it is upon this variation that selective processes are thought to act.

On coral reefs, fish are exposed to a number of predators that will exhibit differing prey selectivity functions. The species composition and density of predators on coral reefs also vary markedly with habitat (Connell \& Kingsford 1998, Stewart \& Beukers 2000) or among sites within a habitat (Holbrook \& Schmidt 2003). Thus, there is the potential for considerable spatial variability in the direction and intensity of predator selection. Selection may be effectively negated by predators with complementary prey selection fields, whereby all size classes of the prey become equally exploited. At the other end of the spectrum, selectivity may be strongly biased by a predator that is abundant at a particular location, or by the action of a number of predators that have similar prey-selection profiles. Given the complexity that may result from the multi-species predator pool, it is important to determine whether selection is occurring when fish are exposed to the natural multi-species predator pool, and whether this selection changes with the composition of a predator assemblage.

The present study examined whether there was sizeselective loss of newly settled damselfish Pomacentrus amboinensis (Pomacentridae) through the action of a multi-species predator pool. Paired choice trials were undertaken to explore whether prey selection was consistent among 3 sites within a reef that differed in predator composition.

\section{MATERIALS AND METHODS}

Study species and sites. The damselfish Pomacentrus amboinensis is common within coral reef fish communities in the Indo-Pacific. They settle to a wide variety of habitats on the northern Great Barrier Reef, but are found in highest densities associated with small reef patches at the base of shallow reefs. Pomacentrus amboinensis has a pelagic larval duration of 15 to $23 \mathrm{~d}$ and settles at 10.3 to $15.1 \mathrm{~mm}$ standard length (Kerrigan 1996) with its juvenile body plan largely complete (McCormick et al. 2002). Once settled, $P$. amboinensis is site-attached, making it an ideal species for both field observations and experimental manipulation.

The present study was conducted on small patch reefs $(20 \times 20 \times 20 \mathrm{~cm})$ built for each replicate trial at 3 lagoonal study sites (Lagoon, Back-reef and Vicki's, $200 \mathrm{~m}$ to $1.2 \mathrm{~km}$ apart) at Lizard Island $\left(14^{\circ} 38^{\prime} \mathrm{S}\right.$, $\left.145^{\circ} 28^{\prime} \mathrm{E}\right)$, northern Great Barrier Reef, Australia, during November and December 2003. At each site, patches were arranged on sand, approximately $2 \mathrm{~m}$ from the reef base and approximately 3 to $4 \mathrm{~m}$ apart within a $50 \mathrm{~m}$ wide section of reef edge. Each patch consisted of a combination of live and dead Pocillopora damicornis (a bushy scleractinian). Such patch reefs are common settlement sites for this species (McCormick \& Hoey in press). All patches were open to the full array of reef-based and transient predators at each site.

Predator abundance estimates. We used 2 different census techniques to gain an estimate of the abundances of potential predatory fish species, some which are known to be difficult to visually census due to their cryptic habits (Stewart \& Beukers 2000). Point censuses were carried out at each of the sites to obtain estimates of 'reef based' predators. Nine replicate 3 min point censuses were conducted at randomly selected points along each of the study sites. Point censuses were oriented towards the reef face, $2 \mathrm{~m}$ from the reef base, and with a $6 \mathrm{~m}$ field of view. All individuals of any species previously implicated to be a predator on small reef fish (Martin 1994, Stewart \& Jones 2001) within the $6 \times 2 \mathrm{~m}$ area were recorded. A second census method was used to target the lizardfish Synodus variegatus, a cryptic ambush predator found mostly on sand and rubble at the reef base. In order to obtain a precise measure of lizardfish abundance, 3 replicate $45 \times 2 \mathrm{~m}$ transects were slowly completed along the sand, directly adjacent to the reef base at each site.

Collection and tagging of settlement stage fish. Settlement-stage Pomacentrus amboinensis were collected at the back-reef of Lizard Island using light traps (for design see Stobutzki \& Bellwood 1997). The light traps were set at dusk and left in place overnight before being collected at 07:00 to 07:30 h the following morning. Fish collected from each trap were immediately transported to the laboratory where they were maintained in 251 flow-through aquaria systems.

Individual Pomacentrus amboinensis were placed into small clip-seal polyethylene bags along with a small amount of aerated seawater, and measured for standard length using callipers $( \pm 0.1 \mathrm{~mm})$. Fish were paired such that one individual ('large' individual) was 0.8 to $1.0 \mathrm{~mm}$ larger in standard length than the other ('small' individual). This size difference was standardised for all prey pairs throughout the experiments. 
Overall, the size of individuals caught in light traps during the course of the experiment ranged between 11.00 and $13.8 \mathrm{~mm}$ standard length. Thus, the 0.8 to $1 \mathrm{~mm}$ size difference used in the selection trials represented $\sim 9 \%$ of the size of the smallest individuals and $\sim 7 \%$ of the size of the largest individuals. Each large and small individual was then tagged with either a red or black subcutaneous fluorescent elastomer tattoo using a 27-gauge hypodermic needle for the purpose of individual identification, as per Hoey \& McCormick (in press). Tag colours were alternated between replicate patches to avoid the possibility of predators selecting prey based on tag colour. Hoey \& McCormick (in press) found that the tagging technique had no influence on survival or growth of $P$. amboinensis in aquaria over a 2 wk period.

Experimental protocol. All Pomacentrus amboinensis were measured, tagged and released onto the patches within $6 \mathrm{~h}$ of collection from the light traps. Prior to releasing a tagged pair, the patch reef was cleared of all resident fishes and large invertebrates using small hand nets, and subsequently rebuilt. A single $P$. amboinensis pair was then placed onto patch reefs at the Lagoon, Back-reef and Vicki's study sites, and shielded from predators for 5 to $10 \mathrm{~min}$ until acclimated to the new environment. Within $30 \mathrm{~s}$ of release, fish were observed feeding on food items from the water column, which suggested a rapid acclimatisation to their new environment.

Survival of each of the experimental pairs was monitored 3 times $\mathrm{d}^{-1}$ (morning, mid-day, evening) by visual census. Each replicate size-trial ended when one or both of the tagged fish were found to be missing from a patch, at which point the identity of the remaining fish was recorded and the surrounding reef area was searched to determine whether the missing individual had emigrated. If a result was not obtained within $5 \mathrm{~d}$, the Pomacentrus amboinensis pair was removed and the trial was abandoned. Trials where both individuals were found to be missing were discarded from the replicate group. Fifty-five separate patch reefs were constructed and used at the Lagoon site, 57 at the Back-reef site, and 49 at the Vicki's site. Using these patches, a total of 32 successful trials (plus 23 unsuccessful trials) were conducted at the Lagoon site, 34 (plus 23 unsuccessful) at the Back-reef site, and 30 (plus 19 unsuccessful) at the Vicki's site. Only 2 cases of emigration away from a patch reef by a tagged individual were observed during the prey size trials. Both of these cases occurred at the Lagoon site, and both replicates were discarded.

Analysis. Lizardfish abundances were compared among sites using a 1-way ANOVA and Tukey's Honestly Significant Difference (HSD) means comparisons. A 1-way multivariate ANOVA (using a Pillai's trace test statistic) was used to compare the assemblage of reef-based predators among sites. Assumptions of homogeneity of variance and normality were examined prior to analysis. The frequency of large and small prey survivors at each sites were compared using a chi-squared goodness of fit test (incorporating Yates' correction for $\mathrm{df}=1$ ). Fisher's exact test was used to compare the relative survivor counts between the sites.

Relative survival of Pomacentrus amboinensis pairs was plotted over time in order to obtain mortality estimates during the experiment. It should be noted that this was calculated as the number of mortality events recorded as a proportion of trials censused at that particular time point. A Cox-Mantel test (a component of survival analysis) was used to compare relative survival curves among sites. Relative survival refers to the survival of the $P$. amboinensis pair on each patch reef, rather than to the individuals. As a result, the disappearance of either one or both individuals of a prey pair from a patch reef was classed as a single mortality event. This method was used as survival of individuals could not be tracked throughout the entire experiment: survivors of successful trials were removed from the experiment once a result was obtained. Although this method has the potential to underestimate true survivorship, it provides a good estimate of the relative levels of mortality occurring throughout the time of the trials.

To determine whether the magnitude of survival during the experiment was within naturally occurring published levels, an approximate absolute survival estimate was calculated for the 6 to $24 \mathrm{~h}$ experimental period. All individuals used in valid trials were pooled together from all 3 of the study sites $(n=254)$ in order to obtain this estimate. This was only possible for the first census period, due to the termination of a trial after the loss of 1 individual within the replicate pair.

\section{RESULTS}

\section{Predator abundances}

The predator assemblage significantly differed among sites (1-way MANOVA, Pillai's trace 10,6 $_{1}=1.931$, $\mathrm{p}<0.0013$; Fig. 1). The moonwrasse Thalassoma lunare and the dottyback Pseudochromis fuscus were the only species recorded at all 3 sites, with $P$. fuscus densities being low. T. lunare was the most abundant predator across the 3 sites, with the highest densities occurring at Vicki's. The rock cod Cephalopholis boenak was observed only at Back-reef and Vicki's sites, with higher abundances being recorded at Back-reef. The snapper Lutjanus carponotatus and rock cod $C$. cyanostigma were observed only at the lagoon site, 


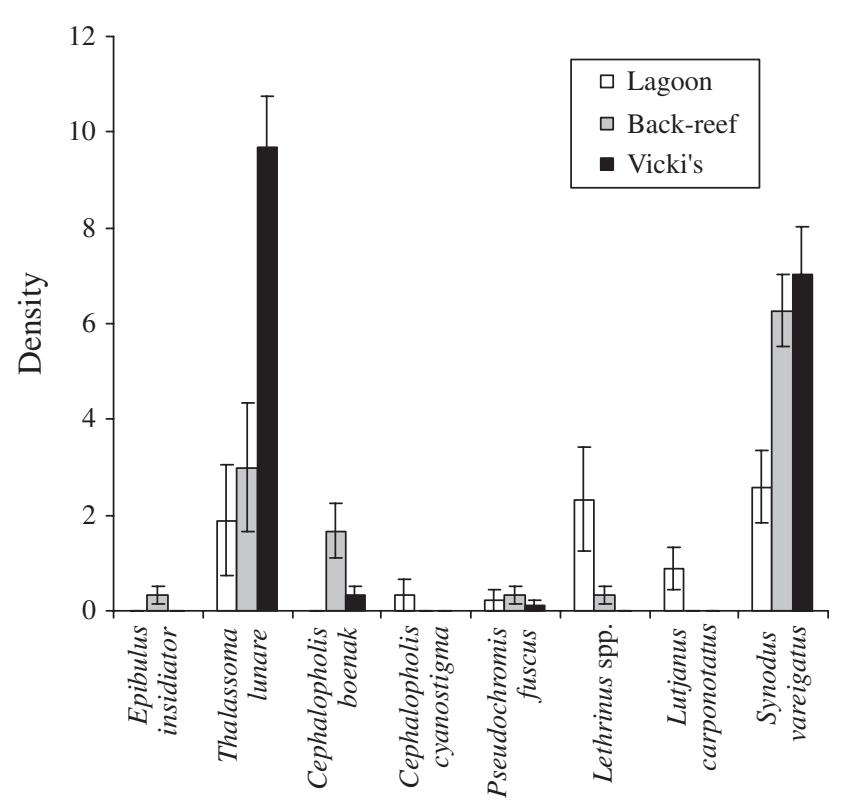

Fig. 1. Mean abundances of potential predators at the Lagoon, Back-reef and Vicki's study sites. Data for all but Synodus variegatus were obtained from 3 min point censuses, while data for $S$. variegatus was obtained from trip transects (per $100 \mathrm{~m}^{2}$ ). Error bars are SE

while the wrasse Epibulus insidiator was only recorded at Back-reef. Lethrinus spp. (mostly L. nebulosus and L. harak) were observed at both the Lagoon and Backreef sites, with higher abundances being recorded at the Lagoon site.

The abundance of lizardfish Synodus variegatus differed among sites $\left(F_{2,6}=8.267, \mathrm{p}=0.019\right)$, with larger numbers being observed at both Vicki's (mean $=3.52$ per $50 \mathrm{~m}^{2}$ ) and Back-reef sites (3.15 per $50 \mathrm{~m}^{2}$ ) relative to the Lagoon site $\left(1.30\right.$ per $50 \mathrm{~m}^{2}$ ). A Tukey HSD test revealed a difference in lizardfish abundances between the Lagoon site and both Back-reef $(p=0.045)$ and Vicki's sites $(\mathrm{p}=0.021)$.

Overall, potential predators (reef and sand/rubbleassociated) of small fishes were in higher densities at Vicki's than at the Lagoon and Back-reef sites (45.6 versus 24.9 and 26.8 per $50 \mathrm{~m}^{2}$, respectively).

\section{Survival}

Approximately $98 \%$ of trials conducted at the Vicki's site, and $87 \%$ of those at the Back-reef site, were completed within the first $24 \mathrm{~h}(2.22$ and $13.2 \%$ relative survivorship respectively; Fig. 2). After this time survivorship stabilised, with only a further $2.22 \%$ drop in survivorship occurring during the second $24 \mathrm{~h}$ period at Vicki's, and a further $7.53 \%$ drop in survivorship occurring gradually at Back-reef over the following 96 h. Relative mortality was lower at the Lagoon site, with a $62.22 \%$ loss over the first $24 \mathrm{~h}$, followed by a further $8.89,15.56$ and $13.33 \%$ loss over the subsequent $72 \mathrm{~h}$. Relative survival between the Lagoon and Vicki's sites differed significantly $\left(\right.$ Cox-Mantel ${ }_{116,120}=2.053$, $\mathrm{p}=0.04$ ), but neither differed from the Back-reef survival trajectory. Overall, 126 fish were lost from a total of 254 fish deployed in paired trials during the first 6 to $24 \mathrm{~h}$, yielding an absolute mortality estimate of $49.6 \%$, which is similar to the natural mortality levels found for the species by other studies (20 to $60 \%$ mortality in the first day in a similar patch reef habitat, McCormick \& Hoey 2004).

Only 2 cases of emigration away from a patch reef by a tagged individual were observed during the trials. Both of these cases occurred at the Lagoon site, and both replicates were subsequently discarded.

\section{Size-selection trials}

When selectivity was examined at the site level, the patterns of loss differed markedly among sites (Fig. 3). Large individuals survived more often at the Vicki's site $(73.3 \%$, as opposed to $26.6 \%$ for small individuals; $\chi_{\text {df } 1}^{2}=5.633, \mathrm{p}=0.018$ ), while the small individuals survived more frequently at Back-reef $(58.8 \%$, as opposed to $41.2 \%$ for large individuals); however, this latter trend was not statistically significant $\left(\chi_{\text {df } 1}^{2}=\right.$ $0.735, p=0.391)$. Interestingly, survivorship was found to be random at the Lagoon site, with equal numbers of large and small individuals surviving. A Fisher's exact test revealed that Vicki's and Back-reef sites were the only sites to show statistically significantly different

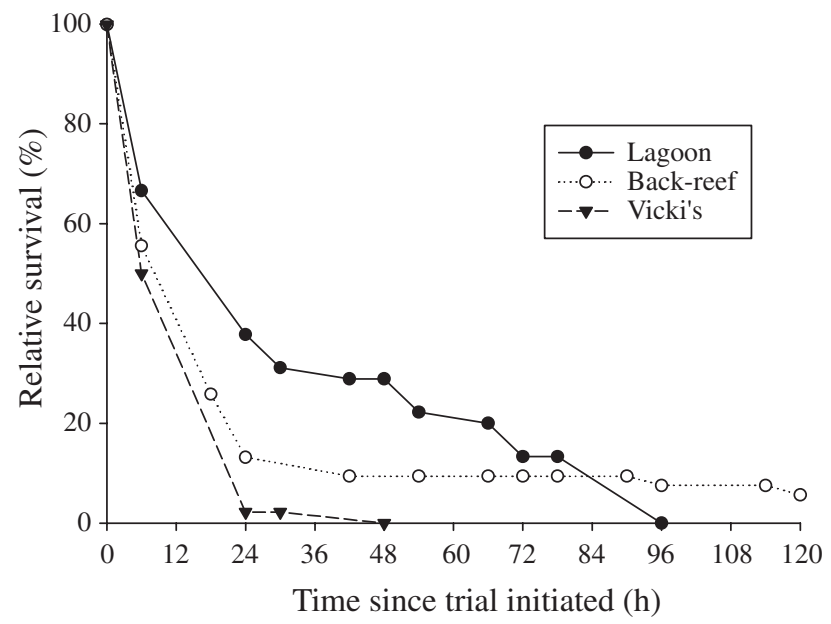

Fig. 2. Pomacentrus amboinensis. Relative survival of newly settled individuals over time since trial initiation, during sizebased trials at the Lagoon, Back-reef and Vicki's sites 


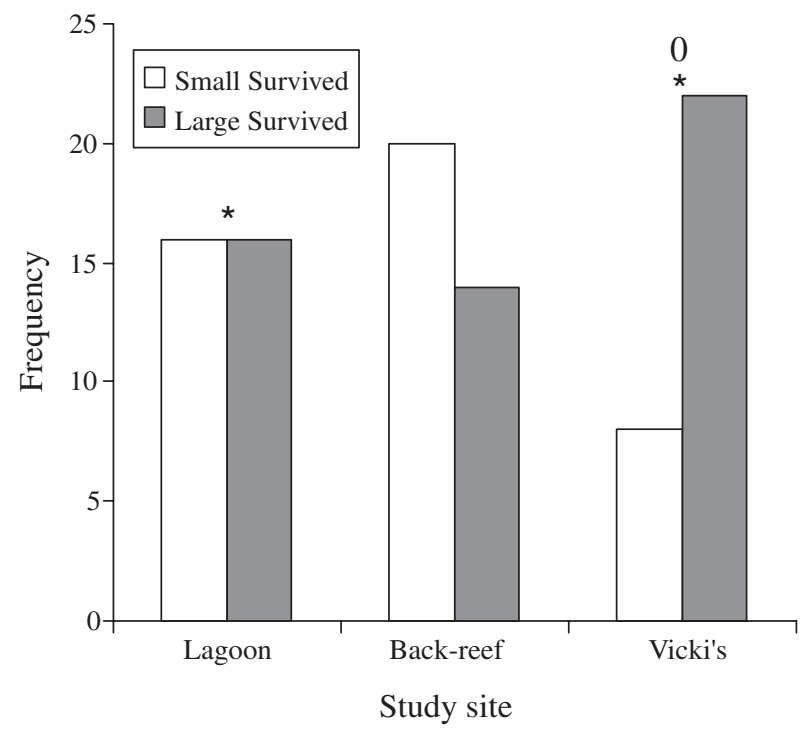

Fig. 3. Pomacentrus amboinensis. Survivor counts of newly settled individuals from size-based trials at the Lagoon ( $\mathrm{n}=$ 32), Back-reef $(n=34)$ and Vicki's sites $(n=30) .0=$ significant difference between within-site survivor counts, * = significant difference between among-site relative survivor counts. Significance determined at $\mathrm{p}<0.05$

trends in survival ( $\mathrm{p}=0.009)$, although the survivor counts for the Lagoon and Vicki's sites were only marginally non-significant $(p=0.052)$.

\section{DISCUSSION}

This study provides the first evidence that the direction of selection and intensity of predation during the early post-settlement period of a tropical reef fish may differ among sites within a reef. As emigration of tagged fish away from the patch reefs was minimal, it can be assumed that mortality incurred during the trials was the result of predation. This study joins a number of recent studies to suggest that mortality in the days immediately after settlement follows an exponential decay function (Type III mortality; Webster 2002, Hoey \& McCormick 2004, McCormick \& Hoey 2004). This initially high mortality, coupled with the selective nature of the loss, suggests that the influence of selection during settlement and the early juvenile stage will be amplified.

Recent research on tropical fishes emphasises the size-selective nature of loss. The findings of size selection in the present study support a study that monitored the survival of tagged, naturally settled Pomacentrus amboinensis in the field. McCormick \& Hoey (2004) found that a size difference of $0.4 \mathrm{~mm}$ was sufficient to significantly increase the chances of an individual surviving during the first day after settlement.
A number of other studies have inferred selective mortality by comparing the characteristics of the survivors to the initial size distribution at settlement using back calculations of fish size from otolith microstructure. Searcy \& Sponaugle (2001) identified patterns of selective mortality during the settlement of 2 Caribbean wrasses Thalassoma bifasciatum and Halichoeres bivittatus, and suggested that individuals surviving to later life stages had higher pre-settlement growth rates and were consequently larger at settlement. Similarly, Vigliola \& Meekan (2002) found negative size-selection 1 to 2 mo after settlement for juveniles of the damselfish Neopomacentrus filamentosus. Evidence from these and other studies of manipulated juveniles (e.g. Jones 1987, Booth 1995, Carr \& Hixon 1995, Beukers \& Jones 1997, Sogard 1997) suggests that selective mortality may be commonplace among recently settled fishes.

The present study highlights the importance of localscale community dynamics in influencing early postsettlement mortality schedules. Site differences were manifested in both the intensity of predation and the direction and intensity of selection. While a large majority of the mortality occurred within the first $24 \mathrm{~h}$ after settlement at both Back-reef and Vicki's sites, the proportion of mortality that occurred during the same period at the Lagoon site was much lower. This indicates that the intensity of predation was stronger at both Back-reef and Vicki's sites than at the Lagoon site. This high predator intensity coincided with a variable direction of selection at both Back-reef and Vicki's sites; in contrast, no trend was detected at the lower mortality Lagoon site. McCormick \& Hoey (2004) recently showed that the intensity of selection, and traits selected, were dependent on the predator species pool to which prey were exposed. As a result, the relative abundances of the potential predatory species at each of the 3 sites could aid in the interpretation of the results.

Martin (1994) used gut content analysis and field observations to identify the lizardfish Synodus variegatus, dottyback Pseudochromis fuscus and rock cod Cephalopholis boenak as primary predators of newly settled fish at Lizard Island. Although Martin (1994) found only limited evidence to suggest that the moonwrasse Thalassoma lunare eats juvenile fishes, the species has often been implicated as being an important predator on small reef fishes (e.g. McCormick \& Hoey 2004). Indeed, during the course of the present study, numerous opportunistic predation events by this species were observed. It is possible that the relatively high abundances of $S$. variegatus, $C$. boenak and T. lunare at both Back-reef and Vicki's sites, as compared to those recorded at the Lagoon site, contributed to the differences in predation intensity among sites. 
Differing current speeds among the 3 sites may also have influenced the observed patterns of predation intensity and size-selection. While only rudimentary observations of current speed were taken during this study, it was noted that current speed along the shallow reef base was high at Vicki's $\left(\sim 14 \mathrm{~cm} \mathrm{~s}^{-1}\right)$, moderate at Back-reef $\left(\sim 10 \mathrm{~cm} \mathrm{~s}^{-1}\right)$ and low at the Lagoon site $\left(\sim 1 \mathrm{~cm} \mathrm{~s}^{-1}\right)$. It was also observed that some newly settled fish struggled to remain close to shelter during periods of strong water flow at the Vicki's site. This behaviour may have increased the susceptibility of these individuals to predation, while those at the Lagoon site - where water currents were not as strong - were relatively free of this stress. If swimming stamina is correlated with fish size (as has been shown for damselfishes; Stobutzki 1998) then a high current could be expected to increase the vulnerability of small fish to opportunistic predators. Our evidence indicates that the variable size-selectivity found among sites may be the product of a 3-way interaction involving prey characteristics, the predator assemblage and their cumulative selection profile, and environmental characteristics of the site (such as water flow, accentuating vulnerability).

The present study does suggest that bigger can be better when it comes to surviving within a fish community that contains many different types and sizes of predators. However, it is not possible to determine whether the mechanism underlying this trend is due to the positive benefits for survival of being larger than average ('bigger is better' hypothesis), or simply results from a size range of prey that fits within the lefthand side of an optimality curve of a predator common at a particular location. It is the interaction of the size range of prey, the selectivity fields of generally gapelimited predators (Scharf et al. 2000), and the relative abundance of those predators that will determine the survival probabilities of prey. A better understanding of the interactions between newly settled fish and a variety of competing predators will provide an insight into the factors that influence the direction and intensity of prey selection.

Acknowledgements. We thank S. Smith, V. Messmer, M. Gagliano and G. Hill for their assistance in the field. T. Lemberget and M. Gagliano provided comments on the manuscript. This study was funded through the Australian Research Council Centre of Excellence for Coral Reef Studies.

\section{LITERATURE CITED}

Bailey KM, Houde ED (1989) Predation on eggs and larvae of marine fishes and the recruitment problem. Adv Mar Biol 25:1-83

Beukers JS, Jones GP (1997) Habitat complexity modifies the impact of piscovores on a coral reef fish. Oecologia 114:50-59
Booth DJ (1991) The effects of sampling frequency on estimates of recruitment of the domino damselfish Dascyllus albisella. J Exp Mar Biol Ecol 145:149-159

Booth DJ (1995) Juvenile groups in a coral-reef damselfish: density-dependent effects on individual fitness and population demography. Ecology 76:91-106

Booth DJ (2002) Larval supply, condition and persistence of the coral reef fish, Pomacentrus moluccensis. Proc 9th Int Coral Reefs Symp 1:463-466

Booth DJ, Beretta GA (2004) Influence of recruit condition on food competition and predation risk in a coral reef fish. Oecologia 140:289-294

Caley MJ (1998) Age-specific mortality rates in reef fishes: evidence and implications. Aust J Ecol 23:241-245

Carr MH, Hixon MA (1995) Predation effects on early postsettlement survivorship of coral reef fishes. Mar Ecol Prog Ser 124:31-42

Connell SD, Kingsford MJ (1998) Spatial, temporal and habitat-related variation in the abundance of large predatory fish at One Tree Reef, Australia. Coral Reefs 17:49-57

Crouse DT, Crowder LB, Caswell H (1987) A stage-based population model for loggerhead sea turtles and implications for conservation. Ecology 68:1412-1423

Doherty PJ, Fowler A (1994) An empirical test of recruitment limitation in a coral reef fish. Science 263:935-939

Doherty PJ, Dufour V, Galzin R, Hixon MA, Meekan MG, Planes S (2004) High mortality during settlement is a population bottleneck for a tropical surgeonfish. Ecology 85: $2422-2428$

Hoey AS, McCormick MI (2004) Selective predation for low body condition at the larval-juvenile transition of a coral reef fish. Oecologia 139:23-29

Hoey AS, McCormick MI (in press) Effects of subcutaneous fluorescent tags on the growth and survival of a newly settled coral reef fish, Pomacentrus amboinensis (Pomacentridae). Proc 10th Int Coral Reef Symp

Holbrook SJ, Schmitt RJ (2003) Spatial and temporal variation in mortality of newly settled damselfish: patterns, causes and co-variation with settlement. Oecologia 135:532-541

Jones GP (1987) Some interactions between residents and recruits in two coral reef fishes. J Exp Mar Biol Ecol 114: 169-182

Kerrigan BA (1996) Temporal patterns in size and condition at settlement in two tropical reef fishes (Pomacentridae: Pomacentrus amboinensis and P. nagasakiensis). Mar Ecol Prog Ser 135:27-41

Kerrigan BA (1997) Variability in larval development of the tropical reef fish Pomacentrus amboinensis (Pomacentridae): the parental legacy. Mar Biol 127:395-402

Martin J (1994) Predation on juvenile coral-reef fish at Lizard Island, Northern Great Barrier Reef: an ecological and behavioural study. BSc Honours thesis, James Cook University, Townsville

McCormick MI (1998) Condition and growth of reef fish at settlement: is it important? Aust J Ecol 23:258-264

McCormick MI, Hoey AS (2004) Larval growth history determines juvenile growth and survival in a tropical marine fish. Oikos 106:225-242

McCormick MI, Hoey AS (in press) Biological and physical correlates of settlement and survival for a coral reef fish, Pomacentrus amboinensis (Pomacentridae). Proc 10th Int Coral Reef Symp

McCormick MI, Molony BW (1993) Quality of the reef fish Upeneus tragula (Mullidae) at settlement: is size a good indicator of condition? Mar Ecol Prog Ser 98:45-54

McCormick MI, Makey L, Dufour V (2002) Comparative study of metamorphosis in tropical reef fishes. Mar Biol 141:841-853 
Planes S, Lecaillon G (2001) Caging experiment to examine mortality during metamorphosis of coral reef fish larvae. Coral Reefs 20:211-218

Rice JA, Crowder LB, Marschall EA (1997) Predation on juvenile fishes: dynamic interactions between size-structured predators and prey. In: Chambers RC, Trippel EA (eds) Early life history and recruitment in fish populations. Chapman \& Hall, New York, p 332-356

Scharf FS, Juanes F, Rowntree RA (2000) Predator size-prey size relationships of marine fish predators: interspecific variation and effects of ontogeny and body size on trophicniche breadth. Mar Ecol Prog Ser 208:229-248

Schmitt RJ, Holbrook SJ (1999) Mortality of juvenile damselfish: implications for assessing processes that determine abundance. Ecology 80:25-30

Searcy SP, Sponaugle S (2001) Selective mortality during the larval-juvenile transition in two coral reef fishes. Ecology 82:2452-2470

Sogard SM (1997) Size-selective mortality in the juvenile stage of teleost fishes: a review. Bull Mar Sci 60:1129-1157

Editorial responsibility: Charles Birkeland (Contributing Editor), Honolulu, Hawaii, USA
Stewart BD, Beukers JS (2000) Baited technique improves censuses of cryptic fish in complex habitats. Mar Ecol Prog Ser 197:259-272

Stewart BD, Jones GP (2001) Association between the abundance of piscivous fishes and their prey on coral reefs: implications for prey-fish mortality. Mar Biol 138: 383-397

Stobutzki IC (1998) Interspecific variation in sustained swimming ability of late pelagic stage reef fish from two families (Pomacentridae and Chaetodontidae). Coral Reefs 17: $111-120$

Stobutzki IC, Bellwood DR (1997) Sustained swimming abilities of the late pelagic stages of coral reef fishes. Mar Ecol Prog Ser 149:35-41

Vigliola L, Meekan MG (2002) Size at hatching and planktonic growth determine post-settlement survivorship of a coral reef fish. Oecologia 131:89-93

Webster MS (2002) Role of predators in the early post-settlement demography of coral-reef fishes. Oecologia 131: $52-60$

Submitted: February 22, 2005; Accepted: December 14, 2005 Proofs received from author(s): June 21, 2006 